\title{
Correction to: Study on optimization of a simulation method for abrasive water jet machining
}

\author{
Xiaojin Miao ${ }^{1} \cdot$ Meiping $\mathrm{Wu}^{1} \cdot$ Zhengrong Qiang $^{1} \cdot$ Quanlong Wang ${ }^{1} \cdot$ Xingang Miao $^{1}$
}

Published online: 23 December 2019

(C) Springer-Verlag London Ltd., part of Springer Nature 2019

Correction to: The International Journal of Advanced Manufacturing Technology, Volume 93, Issue 1, pp 587-593

https://doi.org/10.1007/s00170-017-0502-Z

Author Meiping Wuwmp169@jiangnan.edu.cn should also be declared as the corresponding author of the article https:// doi.org/10.1007/s00170-017-0502-z.

The online version of the original article can be found at https://doi.org/ $10.1007 / \mathrm{s} 00170-017-0502-\mathrm{z}$

\footnotetext{
Xiaojin Miao

miaoxiaojin126@126.com

$\triangle$ Meiping $\mathrm{Wu}$

wmp169@jiangnan.edu.cn

1 School of Mechanical Engineering, Jiangnan University,

Wuxi 214122, China
} 